\title{
Understanding Concordance in Patient- Physician Relationships: Personal and Ethnic Dimensions of Shared Identity
}

\author{
Richard L. Street, Jr, $P b D^{1,2}$ \\ Kimberly J. O'Malley, $\mathrm{PbD}^{3}$ \\ Lisa A. Cooper, MD, MPH \\ Paul Haidet, $M D, M P H^{2}$ \\ 'Department of Communication, Texas \\ A\&M University, College Station \\ ${ }^{2}$ The Houston Center for Quality of Care \\ and Utilization Studies and Baylor College \\ of Medicine, Houston, Texas \\ ${ }^{3}$ Pearson Educational Measurement, \\ Austin, Texas \\ ${ }^{4}$ The Welch Center for Prevention, Epide- \\ miology, and Clinical Research, Johns Hop- \\ kins University, Baltimore, Maryland
}

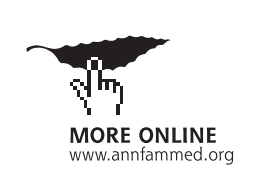

AC Annals Journal Club selection; see inside back cover or http://www. annfammed.org/AJC/.

Conflicts of interest: none reported

\section{CORRESPONDING AUTHOR}

Richard L. Street, Jr, PhD

Department of Communication

Texas A\&M University

College Station, TX 77843-4234

r-street@tamu.edu

\begin{abstract}
PURPOSE Although concordance by race and sex in physician-patient relationships has been associated with patient ratings of better care, mechanisms through which concordance leads to better outcomes remains unknown. This investigation examined (1) whether patients' perceptions of similarity to their physicians predicted their ratings of quality of care and (2) whether perceived similarity was influenced by racial and sexual concordance and the physician's communication.
\end{abstract}

METHODS The research design was a cross-sectional study with 214 patients and 29 primary care physicians from 10 private and public outpatient clinics. Measures included postvisit patient ratings of similarity to the physician; satisfaction, trust, and intent to adhere; and audiotape analysis of patient involvement and physicians' patient-centered communication.

RESULTS Factor analysis revealed 2 dimensions of similarity, personal (in beliefs, values) and ethnic (in race, community). Black and white patients in racially concordant interactions reported more personal and ethnic similarity (mean score, 87.6 and 78.8 , respectively, on a 100-point scale) to their physicians than did minority patients (mean score, 81.4 and 41.2 , respectively) and white patients (mean score, 84.4 and 41.9 , respectively) in racially discordant encounters. In multivariable models, perceived personal similarity was predicted by the patient's age, education, and physicians' patient-centered communication, but not by racial or sexual concordance. Perceived personal similarity and physicians' patient-centered communication predicted patients' trust, satisfaction, and intent to adhere.

CONCLUSIONS The physician-patient relationship is strengthened when patients see themselves as similar to their physicians in personal beliefs, values, and communication. Perceived personal similarity is associated with higher ratings of trust, satisfaction, and intention to adhere. Race concordance is the primary predictor of perceived ethnic similarity, but several factors affect perceived personal similarity, including physicians' use of patient-centered communication.

Ann Fam Med 2008;6:198-205. DOI: 10.1370/afm.821.

\section{INTRODUCTION}

$\mathrm{T}$ he physician-patient relationship has an important impact on disparities in medical care. For example, African-American and Hispanic patients are more likely to report dissatisfaction with their relationships with physicians, report less continuity of care, and perceive poorer quality of care. ${ }^{1}$ Relationship-oriented factors, such as trust and physician communication style, have been linked to disparities in patient satisfaction, ${ }^{2,3}$ delivery of preventive care services, ${ }^{4-6}$ appropriate use of referrals, ${ }^{7.9}$ and patient follow-through on treatment. ${ }^{6,10,11}$

Concordance has emerged as an important dimension of the patientphysician relationship that may be linked to health care disparities. As 
a concept, concordance is most often defined as a similarity, or shared identity, between physician and patient based on a demographic attribute, such as race, sex, or age. Some evidence supports this view, especially with respect to racial concordance. Patients' trust, satisfaction, utilization of services, and involvement in decision making have been reported higher when the patient and physician share the same race or ethnicity. ${ }^{12-17}$ On the other hand, other studies have found no significant effects associated with racially concordant physician-patient relationships, ${ }_{1}^{18-22}$ and the benefits of other types of concordance (eg, sex or age) are even more equivocal. ${ }^{23-26}$

Whereas concordance studies have produced some intriguing findings, they also raise important methodological questions. First, concordance implies a point of commonality that can enhance the ways patients and physicians relate to one another. One dimension of concordance (eg, race), however, does not occur in isolation (eg, sex). Several factors (eg, sexual orientation, parental status, communication style) may have an equal, if not greater, effect on the physician-patient relationship. Second, the relationship of demographic concordance to postconsultation outcomes is mediated though cognitive and affective processes; yet, few studies have identified or measured the role of these mediating variables. ${ }^{13,27}$

In this investigation, we hypothesized that the link between concordance and outcomes is mediated through perceptions of relational similarity. In other words, patients interacting with a physician whom they see as similar to themselves may perceive less social distance, assume that the physician has similar beliefs and values about health care, and be more inclined to trust that physician. Investigating the perceptual underpinnings of concordance effects is important because, although a person's demographic characteristics are for the most part fixed, perceptions of the physician-patient relationship are modifiable and could be the focus of interventions to improve communication.

This investigation had 3 objectives. The first was to create a self-report measure of perceived similarity that was based on dimensions of shared identity. The second was to evaluate the influence of concordance by race and sex on perceived similarity alone and in the context of other factors, including the relational history between physician and patient and the way in which physicians communicated with patients. Third was to examine the relationship of patients' perceptions of similarity to physicians to quality of care outcomes, including patient participation in the consultation, trust in the physician, satisfaction with care, and intent to adhere to treatment recommendations.

\section{METHODS}

\section{Research Participants}

As part of Project CONNECT, ${ }^{28}$ we recruited patients and physicians at 10 primary care clinic settings in the Houston, Texas, area. Clinic settings included public (Department of Veterans Affairs or county hospital) and private (integrated practice network) health care systems. To recruit physicians, we sent a flyer to various clinics inviting physicians to one of several luncheons to discuss their participation in a research project on physician-patient communication. At the luncheon, the physicians were given an overview of the project (although the specific research questions were not introduced) and were invited to participate. Some physicians were invited by telephone because they were not able to attend the luncheon but were interested in the project. A total of 29 physicians agreed to participate. For each of these physicians, 1 patient per half-day clinic was recruited by approaching potential participants as they arrived for their visits. Patients were eligible to participate if they spoke English and were older than 18 years. The study received institutional review board approval, and informed consent was obtained from all patients and physicians.

Before the consultation, patients completed a questionnaire that elicited demographic information, as well as how many times they had previously seen this physician. Concordance by race and sex was determined by comparing patient and physician self-reports. After the visit, patients completed a survey that included the similarity and outcome measures.

\section{Similarity Scale Development}

An item-writing team consisting of a general internist (P.H.) and a psychometrician (K.J.O'M.) created potential items for the similarity measure. The writing team based items on multiple dimensions upon which a person might perceive as having a personal, cultural, or ethnic connection to another, including communication, beliefs, and values, as well as racial, ethnic, religious, or social groups. A convenience sample of 8 patients pilot-tested the items during a 2 -hour focus group. Focus group participants completed the items in relation to their doctor, identified items they deemed inappropriate, and identified problems in wording. After feedback from the focus group, 10 items were selected for the similarities scale (Table 1).

Patients who participated in the study completed the 10 items to rate their perception of similarity to the physician after the consultation. Factor analysis of the patients' responses found 2 factors with eigenvalues greater than 1.0. One factor included items related to race and community and was labeled etbnic similarity. Another factor included items reflecting similarity in 
thinking, values, and communicating, and was labeled personal similarity. The ethnic similarity factor accounted for $65 \%$ percent of item variance, and the personal similarity factor explained an additional $30 \%$ of item variance. The only item not loading on either factor was similarity in spiritual beliefs; this item was therefore excluded from additional analyses. Items with primary loadings on personal similarity $(n=4)$ and ethnic similarity $(n=5)$ were summed then scaled on a 100 point scale to create 2 measures of perceived similarity. Cronbach's $\alpha$ for the personal and ethnic similarity measures was 0.81 and 0.91 , respectively. The measures of personal and ethnic similarity were only moderately correlated $(r=.27)$, indicating that these factors represented distinct perceptions of similarity.

\section{Outcome and Communication Measures}

Outcome measures included patient's self-reports of trust in the physician, ${ }^{29}$ satisfaction with care, ${ }^{30}$ and intent to follow treatment recommendations. Reliability was sufficient for the patient trust $(\alpha=.86)$, satisfaction $(\alpha=.91)$, and intent to adhere to recommendation $(\alpha=.63)$ measures.

An additional outcome measure was patient participation in the encounter. For this assessment, 2 coders independently listened to the audio-recordings of consultations and rated the patient's participation using an adaptation of Lerman's Perceived Involvement in Care scale (PICS). ${ }^{31,32}$ Because PICS was designed as a patient self-report measure, we modified its items to make them appropriate for observer coding. An earlier study validated this approach by showing that this measure was modestly but significantly correlated with frequency measures of patients' communication (eg, number of questions asked, number of concerns

\section{Table 1. Items for Perceived Similarities Measures}

1. The way my doctor and I speak is (PS)

2. The way my doctor and I reason about problems is (PS)

3. My doctor and I have styles of communication. (PS)

4. My doctor and I have general values in life. (PS)

5. My doctor and I have spiritual beliefs. (PS)

6. My doctor and I have ethnic backgrounds. (ES)

7. The types of people I spend my free time with and the types of people my doctor spends his/her free time with are . (ES)

8. My doctor and I are in terms of race. (ES)

9. My doctor and I are in terms of culture. (ES)

10. My doctor and I are in terms of skin color. (ES)

$E S=$ ethnic similarity; PS = personal similarity.

Note: Response options: very similar, moderately similar, slightly similar, slightly different, moderately different, very different. Responses on items 1 through 4 were summed to create a measure of perceived personal similarity. Responses on items 6 through 10 were summed to create a measure of perceived ethnic similarity. expressed) and was predictive of physician and patient postconsultation perceptions. ${ }^{33}$

The coders also rated the physicians' communication during the consultation. Using a measure from earlier studies, ${ }^{34-36}$ coders rated on 5-point scales the degree to which the physician (1) was informative, (2) used supportive communication, and (3) engaged in partnership-building. An earlier study ${ }^{33}$ reported that these scales were highly correlated with one another $(r>.70)$. In other words, physicians who were rated more favorably on one dimension also tended to score highly on the others. Because these features of physician communication are important components of patient-centeredness, ${ }^{37}$ the items, which can be found online as a Supplemental Table at http://www. annfammed.org/cgi/content/full/6/3/196/DC1, were summed to create a single measure of patient-centered communication.

After completing a 2-hour training session, each coder independently rated each interaction. Intraclass correlations (ICC) between the 2 coders' judgments indicated acceptable coder reliability in ratings of the degree to which patients actively participated in the consultation (ICC $=.69$ ) and physicians were patientcentered in their communication $(\mathrm{ICC}=.72)$. Thus, the 2 coders' ratings were averaged to create 1 score per measure.

\section{Data Analysis}

Our analysis included several steps. First, we examined bivariate relationships between racial and sexual concordance and patients' perceptions of personal and ethnic similarity with the doctor. To examine the relative importance of demographic concordance within the context of other factors that might affect patients' perceptions of similarity, we used mixed-model multiple regression procedures. The dependent measures were perceived personal and ethnic similarity and the predictor variables included concordance by race and sex, demographic characteristics, ratings of the physician's patient-centered communication, and number of previous visits with the physician.

Finally, to examine the relationship of perceived personal and ethnic similarity to outcomes, we created multivariate regression models for each of the 4 outcome measures-patient participation, trust, satisfaction, and intent to adhere. Predictor variables included physicians' and patients' demographic characteristics, number of prior visits with the doctor, physicians' patient-centered communication, and patients' perceptions of personal and cultural similarity to their physician. Analyses at each step controlled for patients nested within physicians and treated the individual doctor as a random effect. 


\section{RESULTS}

\section{Overview}

Although 269 patients agreed to participate and have the consultation audio-recorded, audiotape data from 55 patients were missing or incomplete because of equipment malfunction or recording errors. Accordingly, the final analyses included data from 214 patients. The number of patients per physician ranged from 5 to 11 with a median of 7 .

Characteristics of patients and physicians are shown in Table 2. The sample was diverse with respect to physician and patient race, age, and sex. Fifty-eight percent of the sample was concordant with respect to sex, and $32 \%$ was racially concordant. Some of the patients' demographic attributes, however, were not evenly distributed with respect to concordance. Specifically, patients more likely to be in sex-concordant encounters were women $(P<.001)$ and younger $(P<.05)$. Although the percentage of black and white patients in racially concordant or discordant encounters did not differ, all Hispanic patients and all Asian doctors were in racially discordant consultations because of the absence of Hispanic physicians and Asian patients in the sample.

\section{Effects of Demographic Concordance and Other Factors on Perceived Similarity}

Because of the absence of Hispanic doctors, the sample included 5 groups of patients based on their concordance by race with the physician-black patients in racially concordant encounters $(n=39)$, white patients in racially concordant encounters $(\mathrm{n}=33)$, black patients in racially discordant encounters $(n=68)$, white patients in racially discordant encounters $(n=49)$, and Hispanic patients in racially discordant encounters $(n=25)$. Preliminary analyses indicated that black and white patients in racially concordant groups did not differ in their perceptions of personal and ethnic similarity to the physician. Also, black and Hispanic patients in racially discordant interactions were not different in their perceived personal and ethnic similarity to their doctors. White patients in racially discordant encounters, however, saw themselves as slightly more personally similar to their doctors compared with black and Hispanic patients in discordant visits. Thus, further analysis of racial discordance used 3 groups of patients - racially concordant black and white patients, racially discordant ethnic minority (black or Hispanic) patients, and racially discordant white patients.

As shown in Figure 1, patients in racially concordant encounters reported more personal similarity (mean 87.6) to their doctors than did minority patients in racially discordant interactions (mean 81.4). White
Table 2. Characteristics of Patients and Physicians

\begin{tabular}{lll}
\hline Characteristic & $\begin{array}{c}\text { Patients } \\
(\mathbf{n = 2 1 4 )}\end{array}$ & $\begin{array}{c}\text { Physicians } \\
(\mathbf{n = 2 9 )}\end{array}$ \\
\hline $\begin{array}{l}\text { Mean age, years (SD) } \\
\text { Female, \% }\end{array}$ & $55.5(14.7)$ & $40.0(8.1)$ \\
Ethnicity & 59 & 38 \\
$\quad$ Black, \% & & \\
White, \% & 50 & 28 \\
Hispanic, \% & 38 & 31 \\
Asian, \% & 12 & 0 \\
Education & 0 & 41 \\
$\quad$ Less than high school, \% & 14 & 0 \\
High school, \% & 28 & 0 \\
Some college, \% & 36 & 0 \\
College degree, postgraduate, \% & 22 & 100 \\
\hline
\end{tabular}

Figure 1. Racial concordance and patients" perceptions of perceived personal similarity to the physician.

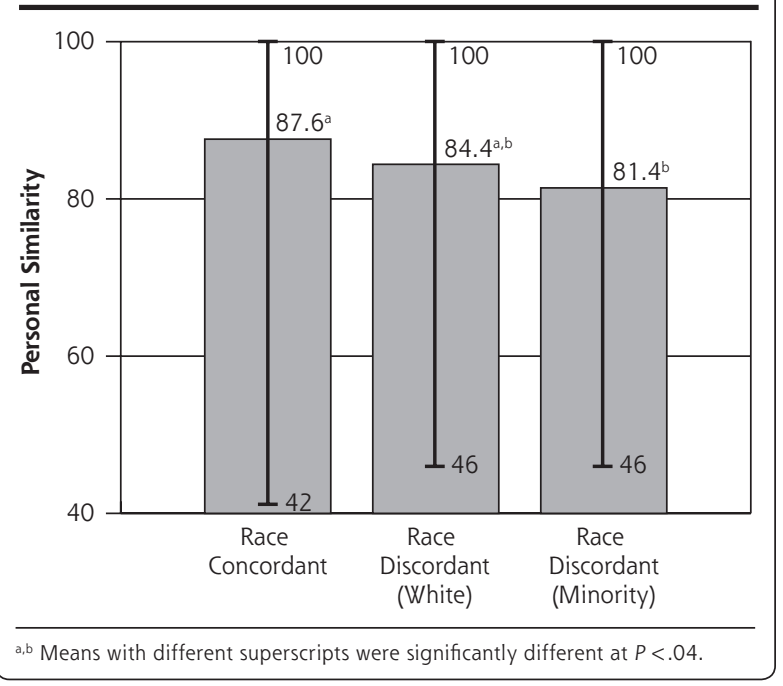

patients in racially discordant interactions did not differ in perceived personal similarity (mean 84.4) relative to the other 2 groups. Also, as shown in Figure 2, patients in racially concordant encounters saw themselves as more ethnically similar to their physicians (mean 78.8) than did minority (mean 41.2) or white (mean 41.9) patients in racially discordant visits. Concordance by sex was not related to perceptions of personal (mean 83.4 and 85.1, respectively, for concordant and discordant dyads) or ethnic (mean 52.2 and 52.7, respectively, for concordant and discordant dyads) similarity. Important to note, however, was the wide variability in similarity scores for both concordant and discordant dyads. The range of perceived personal and ethnic similarity scores was about the same for racially concordant and discordant physicianpatient pairs. In other words, within race- or sex-con- 
cordant dyads, some patients rated themselves as very different from their physicians, and within discordant dyads, some patients saw themselves as very similar to their physicians.

Table 3 displays analyses of the effects of racial and sexual concordance on perceived similarity in the context of other potentially influential factors. In this larger model, older and more educated patients, as well as those whose physicians used more patient-centered communication, perceived themselves to be more personally similar to physicians. Racial concordance, however, remained a strong predictor of perceived

\section{Figure 2. Racial concordance and patients' perceptions of perceived ethnic similarity to the physician.}

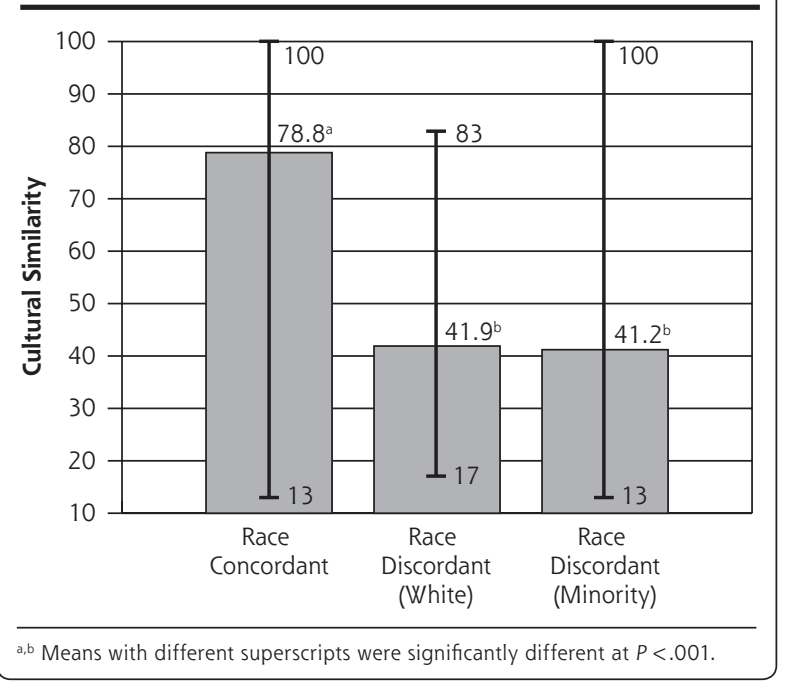

ethnic similarity in the larger model, as did patient age. Concordance by sex was not related to either similarity measure in univariate analyses, and its effects in the larger model remained nonsignificant.

\section{Similarity, Concordance, Physician Communication, and Quality of Care}

Patients' perception of personal similarity to their physicians was a strong predictor of patients' satisfaction with care, trust in the physician, and intent to adhere to treatment recommendations (Table 4). Although perceived personal similarity was correlated with patient involvement in the encounter $(r=.15, \mathrm{P}<.03)$, it was not a significant predictor in the larger multivariate model. Perceived ethnic similarity was not related to outcomes. Controlling for demographic attributes, perceptions of similarity, and effects related to patients nested within physicians, physician-patient concordance by race and sex had little effect on quality of care measures.

The degree to which physicians were patient-centered in their communication not only was related to patients' perceptions of personal similarity to their doctor (Table 3), it also predicted outcomes (Table 4). Specifically, patients were more-active participants, were more satisfied with care, expressed greater trust, and had a stronger intention to adhere to recommendations when their physicians were more informative, supportive, and facilitative. Other findings were noteworthy. Consistent with other studies, ${ }^{38-44}$ more-educated patients were more-active participants in their consultations. Patients reported greater satisfaction with black doctors and expressed more trust when they had a greater number of previous visits to that particular physician. to the Physician ( $\mathrm{N}=214$ Patients)

\begin{tabular}{lcccc}
\hline & \multicolumn{2}{c}{$\begin{array}{c}\text { Perceived Personal } \\
\text { Similarity }\end{array}$} & \multicolumn{2}{c}{$\begin{array}{c}\text { Perceived Ethnic } \\
\text { Similarity }\end{array}$} \\
\cline { 2 - 5 } Factor & Estimate (SE) & $P$ & Estimate (SE) & $P$ \\
\hline Doctor race = black (ref = white) & $1.01(3.16)$ & .94 & $2.63(5.86)$ & .65 \\
Doctor race = Asian (ref = white) & $0.25(3.17)$ & .75 & $-4.89(5.83)$ & .40 \\
Doctor age & $0.04(0.15)$ & .79 & $0.10(0.28)$ & .72 \\
Race discordant = black/Hispanic & $-3.48(2.44)$ & .16 & $-31.56(4.23)$ & .000 \\
$\quad$ patient (ref = race concordant) & $-3.27(2.87)$ & .26 & $-34.06(4.99)$ & .000 \\
Race discordant = white patient & & & & .54 \\
$\quad$ (ref = race concordant) & $1.46(2.00)$ & .47 & $2.21(3.56)$ & .54 \\
Sexual concordance & $0.20(0.07)$ & .005 & $0.26(0.12)$ & .032 \\
Patient age & $-0.89(2.13)$ & .68 & $-4.39(3.74)$ & .24 \\
$\begin{array}{l}\text { Patient sex (ref = female) } \\
\text { Patient education (<HS, HS, some }\end{array}$ & $1.98(0.95)$ & .039 & $2.84(1.65)$ & .085 \\
$\quad$ college, college graduate) & $-0.39(0.83)$ & .64 & $1.73(1.45)$ & .24 \\
Number of previous visits & $0.34(0.13)$ & .008 & $-0.06(0.22)$ & .78 \\
Physicians' patient-centered & & & & \\
$\quad$ communication & & & & \\
\hline HS = high school; ref = reference population. & & & & \\
\hline
\end{tabular}

\section{DISCUSSION}

Little research has explored the mechanisms through which demographic concordance may contribute to better physicianpatient relationships and health outcomes. The results of this investigation indicate that concordance by race (but not sex) contributes in varying degrees to patients' perceptions of a shared identity with their physician, a perception that appears to be an important part of the physicianpatient relationship. Several of this study's results have impor- 
Table 4. Concordance and Perceived Similarity Effects on Outcome Measures ( $N=214$ Patients)

\begin{tabular}{|c|c|c|c|c|c|c|c|c|}
\hline \multirow[b]{2}{*}{ Feature } & \multicolumn{2}{|c|}{$\begin{array}{c}\text { Patient } \\
\text { Involvement }\end{array}$} & \multicolumn{2}{|c|}{ Patient Trust } & \multicolumn{2}{|c|}{$\begin{array}{c}\text { Patient } \\
\text { Satisfaction }\end{array}$} & \multicolumn{2}{|c|}{$\begin{array}{l}\text { Likely } \\
\text { to Adhere }\end{array}$} \\
\hline & Estimate (SE) & $P$ & Estimate (SE) & $P$ & Estimate (SE) & $P$ & Estimate (SE) & $P$ \\
\hline Doctor race $=$ black (ref $=$ white) & $-0.69(1.08)$ & .52 & $2.30(2.15)$ & .29 & $3.15(1.59)$ & .049 & $1.26(3.11)$ & .72 \\
\hline Doctor race $=$ Asian (ref $=$ white) & $0.10(1.10)$ & .93 & $-5.28(2.25)$ & .02 & $-0.01(1.70)$ & .99 & $1.18(3.25)$ & .69 \\
\hline Doctor age & $0.06(0.05)$ & .22 & $-0.03(0.10)$ & .79 & $0.11(0.07)$ & .12 & $0.27(0.15)$ & .062 \\
\hline $\begin{array}{l}\text { Race discordant }=\text { black } / \text { Hispanic } \\
\text { patient (ref = race concordant) }\end{array}$ & $0.24(1.01)$ & .81 & $-2.10(2.37)$ & .38 & $-1.54(1.96)$ & .43 & $4.74(3.42)$ & .17 \\
\hline $\begin{array}{l}\text { Race discordant }=\text { white patient } \\
\quad(\text { ref }=\text { race concordant })\end{array}$ & $1.82(1.16)$ & .12 & $-2.93(2.69)$ & .12 & $0.59(2.20)$ & .79 & $2.45(3.89)$ & .53 \\
\hline Sexual concordance & $0.34(0.72)$ & .64 & $-0.18(1.54)$ & .91 & $1.99(1.19)$ & .09 & $-1.91(2.23)$ & .39 \\
\hline Patient age & $0.04(0.03)$ & .16 & $-0.08(0.06)$ & .20 & $0.06(0.05)$ & .21 & $-0.21(0.09)$ & $.02^{\mathrm{a}}$ \\
\hline Patient sex (ref = female) & $-1.25(0.77)$ & .10 & $-3.26(1.67)$ & .06 & $-1.04(1.35)$ & .44 & $-3.05(2.46)$ & .22 \\
\hline $\begin{array}{l}\text { Patient education (<HS, HS, } \\
\text { some college, college graduate) }\end{array}$ & $0.69(0.35)$ & .052 & $-0.77(0.82)$ & .35 & $-0.51(0.68)$ & .45 & $0.02(1.19)$ & .99 \\
\hline Number of previous visits & $-0.56(0.30)$ & .061 & $1.49(0.66)$ & .026 & $0.18(0.52)$ & .72 & $1.15(0.95)$ & .23 \\
\hline $\begin{array}{l}\text { Physicians' patient-centered } \\
\text { communication }\end{array}$ & $0.35(0.05)$ & .000 & $0.22(0.10)$ & .028 & $0.20(0.08)$ & .01 & $0.39(0.14)$ & .007 \\
\hline $\begin{array}{l}\text { Perceived personal similarity } \\
\text { to the physician }\end{array}$ & $0.00(0.03)$ & .88 & $0.19(0.06)$ & .002 & $0.18(0.05)$ & .001 & $0.31(0.09)$ & .001 \\
\hline $\begin{array}{l}\text { Perceived ethnic similarity } \\
\text { to the physician }\end{array}$ & $-0.00(0.01)$ & .91 & $0.01(0.03)$ & .80 & $-0.03(0.03)$ & .35 & $0.00(0.05)$ & .93 \\
\hline
\end{tabular}

tant implications for future research, education, and clinical practice.

First, the perception of similarity to one's physician is a multidimensional construct with some components more strongly related to outcomes than others. Specifically, patients who believed they were more similar to their doctor with respect to personal beliefs, values, and ways of communicating reported more trust in the physician, more satisfaction with care, and a stronger intention to adhere to recommendations. On the other hand, patients' perceptions of being similar to the physician in terms of race, ethnicity, and community were not related to patient outcomes. Racial concordance does appear to orient patients toward some common ground with the physician, particularly with respect to ethnic similarity. Other factors, however, may be more influential determinants of perceived personal similarity, including the patient's age, education, and the degree to which physicians are patient-centered in their communication. Our results are consistent with those of Stewart et $\mathrm{al}^{9}$ who found that physicians' use of patient-centered behavior was related to patients' beliefs that they and the physician achieved a common understanding of their health conditions.

Our findings have important implications for both medical education and the design of interventions intended to improve health care delivery. Demographic characteristics are generally immutable. Whereas racial concordance has been associated with more positive physician-patient interactions, ${ }_{1}^{12,13,15,17}$ one mechanism for this effect is through perceptions of similarity, which can also be achieved through the physician's use of patient-centered communication. A physician who is skilled in informing, showing respect, and supporting patient involvement can transcend issues of race and sex to establish a connection with the patient that in turn contributes to greater patient satisfaction, trust, and commitment to treatment. Our findings add credibility to initiatives by the Accreditation Council for Graduate Medical Education (http://www.acgme.org/ Outcome) that call for communication skills training as a foundational part of undergraduate, graduate, and continuing medical education.

Our findings extend to cultural competence issues as well. As do the proponents of patient-centered care, advocates of cultural competence emphasize the importance of expressing concern for the patient's well-being, showing respect, and incorporating the patient's views in decision making as valuable tenets of interpersonal relationships in health care. ${ }^{45}$ Our measure of patient-centered communication tapped into some of these behaviors, which may explain why communication, more so than racial concordance, was related to patients' perceptions of a personal connection with their physicians, as well as to patient outcomes. Although racial concordance was not related to outcomes in this study, physician ethnicity was in 2 respects. Patients reported more satisfaction with black 
doctors and less trust with Asian physicians. Even though we cannot draw conclusions from this limited sample of physicians (8 black, 9 white, and 12 Asian), the findings do justify more research on how physician ethnicity affects physician-patient interactions and whether these effects are a function of physician and patient attitudes toward one another or cultural differences in communication style.

Finally, the similarities measure offers a promising direction for concordance research because it allows the participants, rather than researchers, to determine their level of concordance. In this sense, the similarities measure represents a new evolution in the effort to capture some of the complexity of relational concordance. For example, patient ratings of similarity showed moderate to large amounts of variability within the constraints of concordance by race and sex. Some patients in race- and sex-concordant pairs saw themselves as very dissimilar from their physician, and conversely, some patients in discordant pairs saw themselves as very similar to their doctor.

Our study had limitations. First, because we employed a cross-sectional design, the similarities data were collected after the interaction and at the same time as the trust, satisfaction, and adherence measures. We therefore cannot draw conclusions regarding causation. Second, although our findings suggest that effective communication enables a patient and physician to find points of commonality that in turn build trust and satisfaction, a competing explanation might be that higher satisfaction or trust leads to a perception of greater similarity. Further longitudinal work and pre- and post-consultation assessment using the similarities measure are warranted. Third, while relatively balanced with respect to sexual concordance, the study sample was not balanced with respect to racial concordance in that all Hispanic patients and all Asian physicians were in discordant interactions. Fourth, we did not collect information on physicians' medical training. For example, if a higher proportion of Asian physicians were international medical graduates, our finding of lower patient trust with Asian doctors may be confounded by country of medical training and culture. Finally, there may have been some differences related to practice settings (eg, Veterans Affairs vs hospital clinics) that we could not address because the 29 physicians who participated in the study came from various types of practices and clinical sites.

In conclusion, this study developed and tested a measure of perceived similarity that defines concordance from the patient's, rather than the researcher's, perspective. Results indicate that patients' beliefs about similarity to the doctor are multidimensional, consisting of distinct perceptions of both personal and ethnic similarity. Of the 2 dimensions, personal similarity appears more strongly related to patient trust, satisfaction, and intent to adhere. Whereas racial concordance is important to the perception of ethnic similarity, the physician's communication has a significant impact on patients' perceptions of having a personal connection to physicians with respect to thinking, values, and communicating. Future research should strive to better understand how similarities and differences in values, beliefs, and behaviors affect the quality of physician-patient relationships. Such work will inform the development of interventions that foster a sense of connection between patients and physicians which in turn may improve quality of care for all patients and reduce ethnic disparities in health care.

To read or post commentaries in response to this article, see it online at http://www.annfammed.org/cgi/content/full/6/3/198.

Key words: Physician-patient relationship, racial concordance, patientcentered care

Submitted July 30, 2007; submitted, revised, November 13, 2007; accepted November 26, 2007.

Funding support: This research was supported by P01HS10876 from the EXCEED (Excellence Centers to Eliminate Ethnic and Racial Disparities) initiative of the Agency for Healthcare Research and Quality and the National Center for Minority Health and Health Disparities. Dr Haidet was supported in part by a career development award from the us Department of Veterans Affairs. Dr Cooper is supported by a grant from the National Heart, Lung, and Blood Institute (K24HL083113).

\section{References}

1. Institute of Medicine. Unequal Treatment: Confronting Racial and Ethnic Disparities in Health Care. Washington, DC: National Academy Press; 2002.

2. Fiscella K, Meldrum S, Franks P, et al. Patient trust: Is it related to patient-centered behavior of primary care physicians? Med Care. 2004;42(11):1049-1055.

3. Thom DH, Ribisl KM, Stewart AL, Luke DA. Further validation and reliability testing of the Trust in Physician Scale. The Stanford Trust Study Physicians. Med Care. 1999;37(5):510-517.

4. Cabana MD, Jee SH. Does continuity of care improve patient outcomes? J Fam Pract. 2004;53(12):974-980.

5. Williams GC, McGregor HA, King D, Nelson CC, Glasgow RE. Variation in perceived competence, glycemic control, and patient satisfaction: relationship to autonomy support from physicians. Patient Educ Couns. 2005;57(1):39-45.

6. O'Malley AS, Sheppard VB, Schwartz M, Mandelblatt J. The role of trust in use of preventive services among low-income AfricanAmerican women. Prev Med. 2004;38(6):777-785.

7. Jackson JL. Communication about symptoms in primary care: impact on patient outcomes. J Altern Complement Med. 2005;11(Suppl 1):S51-S56.

8. Little P, Everitt H, Williamson I, et al. Observational study of effect of patient centredness and positive approach on outcomes of general practice consultations. BMJ. 2001;323(7318):908-911.

9. Stewart M, Brown JB, Donner A, et al. The impact of patient-centered care on outcomes. J Fam Pract. 2000;49(9):796-804. 
10. DiMatteo MR, Lepper HS. Promoting adherence to courses of treatment: Mutual collaboration in the physician-patient relationship. In: Jackson LD, Duffy BK, eds. Health Communication Research. Westport, CT: Greenwood Press; 1998:75-86.

11. Safran DG, Taira DA, Rogers WH, Kosinski M, Ware JE, Tarlov AR. Linking primary care performance to outcomes of care. J Fam Pract. $1998 ; 47: 213-220$

12. Cooper-Patrick L, Gallo JJ, Gonzales JJ, et al. Race, gender, and partnership in the patient-physician relationship. JAMA. 1999;282(6):583-589.

13. Cooper LA, Roter DL, Johnson RL, Ford DE, Steinwachs DM, Powe NR. Patient-centered communication, ratings of care, and concordance of patient and physician race. Ann Intern Med. 2003;139(11):907-915.

14. King WD, Wong MD, Shapiro MF, Landon BE, Cunningham WE. Does racial concordance between HIV-positive patients and their physicians affect the time to receipt of protease inhibitors? J Gen Intern Med. 2004;19(11):1146-1153.

15. LaVeist TA, Nuru-Jeter A. Is doctor-patient race concordance associated with greater satisfaction with care? J Health Soc Behav. 2002;43(3):296-306

16. LaVeist TA, Nuru-Jeter A, Jones KE. The association of doctor patient race concordance with health services utilization. J Public Health Policy. 2003;24(3-4):312-323.

17. Saha S, Komaromy M, Koepsell TD, Bindman AB. Patient-physician racial concordance and the perceived quality and use of health care. Arch Intern Med. 1999;159(9):997-1004.

18. Beach MC, Roter DL, Wang NY, Duggan PS, Cooper LA. Are physicians' attitudes of respect accurately perceived by patients and associated with more positive communication behaviors? Patient Educ Couns. 2006;62(3):347-354.

19. Lasser KE, Mintzer IL, Lambert A, Cabral H, Bor DH. Missed appointment rates in primary care: the importance of site of care. J Health Care Poor Underserved. 2005;16(3):475-486.

20. Stevens GD, Mistry R, Zuckerman B, Halfon N. The parent-provider relationship: does race/ethnicity concordance or discordance influence parent reports of the receipt of high quality basic pediatric preventive services? J Urban Health. 2005;82(4):560-574.

21. Tai-Seale M, Bramson R, Drukker D, et al. Understanding primary care physicians' propensity to assess elderly patients for depression using interaction and survey data. Med Care. 2005;43(12):1217-1224.

22. Weisse CS, Foster KK, Fisher EA. The influence of experimenter gender and race on pain reporting: does racial or gender concordance matter? Pain Med. 2005;6(1):80-87.

23. Flocke SA, Gilchrist V. Physician and patient gender concordance and the delivery of comprehensive clinical preventive services. Med Care. 2005;43(5):486-492.

24. Franks P, Bertakis KD. Physician gender, patient gender, and primary care. J Womens Health. 2003;12(1):73-80.

25. Garcia JA, Paterniti DA, Romano PS, Kravitz RL. Patient preferences for physician characteristics in university-based primary care clinics. Ethn Dis. 2003;13(2):259-267.

26. Schmittdiel J, Grumbach K, Selby JV, Quesenberry CP Jr. Effect of physician and patient gender concordance on patient satisfaction and preventive care practices. J Gen Intern Med. 2000;15(11):761-769.

27. Cooper LA, Beach MC, Johnson RL, Inui TS. Delving below the surface. Understanding how race and ethnicity influence relationships in health care. J Gen Intern Med. 2006;21(Suppl 1):S21-S27.
28. Haidet $P$, Street RL Jr. From the field: Project CONNECT. Medical Encounter. 2006;20(3):33-34.

29. Hall MA, Zheng B, Dugan $E$, et al. Measuring patients' trust in their primary care providers. Med Care Res Rev. 2002;59(3):293-318.

30. Brown JB, Boles M, Mullooly JP, Levinson W. Effect of clinician communication skills training on patient satisfaction. A randomized, controlled trial. Ann Intern Med. 1999;131(11):822-829.

31. Brody DS, Miller SM, Lerman CE, Smith DG, Caputo GC. Patient perception of involvement in medical care: relationship to illness attitudes and outcomes. J Gen Intern Med. 1989;4(6):506-511.

32. Lerman CE, Brody DS, Caputo GC, Smith DG, Lazaro CG, Wolfson HG. Patients' Perceived Involvement in Care Scale: relationship to attitudes about illness and medical care. J Gen Intern Med. 1990;5(1):29-33.

33. Street RL Jr, Gordon H, Haidet P. Physicians' communication and perceptions of patients: Is it how they look, how they talk, or is it just the doctor? Soc Sci Med. 2007;65(3):586-598.

34. Arntson P, Makoul G, Pendleton D, Schofield T. Patient perceptions of medical encounters in Great Britain: Variation with health loci of control and socidemographic factors. Health Commun. 1989;1(2):75-95.

35. Gordon HS, Street RL Jr, Sharf BF, Kelly PA, Souchek J. Racial differences in trust and lung cancer patients' perceptions of physician communication. J Clin Oncol. 2006;24(6):904-909.

36. Street RL Jr. Physicians' communication and parents' evaluations of pediatric consultations. Med Care. 1991;29(11):1146-1152.

37. Epstein RM, Franks P, Fiscella K, et al. Measuring patient-centered communication in Patient-Physician consultations: Theoretical and practical issues. Soc Sci Med. 2005;61(7):1516-1528.

38. Eggly S, Penner LA, Greene M, Harper FW, Ruckdeschel JC, Albrecht TL. Information seeking during "bad news" oncology interactions: Question asking by patients and their companions. Soc Sci Med. 2006;63(11):2974-2985

39. Siminoff LA, Graham GC, Gordon NH. Cancer communication patterns and the influence of patient characteristics: Disparities in information-giving and affective behaviors. Patient Educ Couns. 2006;62(3):355-360

40. Street RL Jr, Gordon HS, Ward MM, Krupat E, Kravitz RL. Patient participation in medical consultations: why some patients are more involved than others. Med Care. 2005;43(10):960-969.

41. Street RL Jr. Communicative styles and adaptations in physicianparent consultations. Soc Sci Med. 1992;34(10):1155-1163

42. Gordon HS, Street RL Jr, Kelly PA, Souchek J, Wray NP. Physicianpatient communication following invasive procedures: an analysis of post-angiogram consultations. Soc Sci Med. 2005;61(5):1015-1025.

43. Gordon HS, Street RL Jr, Sharf BF, Souchek J. Racial differences in doctors' information-giving and patients' participation. Cancer. 2006;107(6):1313-1320.

44. Johnson RL, Roter D, Powe NR, Cooper LA. Patient race/ethnicity and quality of patient-physician communication during medical visits. Am J Public Health. 2004;94(12):2084-2090.

45. Beach MC, Saha S, Cooper LA. Cultural Competence and PatientCenteredness: Their Relationship and Role in Healthcare Quality. Publication No. 960. New York, NY; The Commonwealth Fund. 2006 http://www.cmwf.org/usr_doc/Beach_rolerelationshipcultcomppatient-cent_960.pdf. 